\title{
High Temperature Oxidation Resistance and Electrical Properties of CrN/Cr Films Prepared by RF Magnetron Technology
}

\author{
Jia-Xin Zhang, Mei-Jie Zhang, Guang-Rui Gu, and Bao-Jia Wu
}

\begin{abstract}
In this work, CrN films were deposited on $\mathrm{Si}$ substrates with a $\mathrm{Cr}$ buffer layer ( $\mathrm{CrN} / \mathrm{Cr}$ films) by $\mathrm{RF}$ magnetron sputtering. The structure, surface morphology, chemical composition, high temperature oxidation resistance and resistivity were studied using $X$-ray diffraction (XRD), scanning electron microscopy (SEM), X-ray spectroscopy (EDX), X-ray photoelectron spectroscopy (XPS) and four-probe resist tester, respectively. The lattice constant of the $\mathrm{CrN} / \mathrm{Cr}$ films with a (111) preferred orientation was estimated to be about $4.1336 \AA$. After high temperature heat treatment, the surface morphology of $\mathrm{CrN} / \mathrm{Cr}$ films changed obviously, and the electrical properties of $\mathrm{CrN} / \mathrm{Cr}$ films were improved. Our results can provide an important reference in the high temperature oxidation resistance research for $\mathrm{CrN}$ films.
\end{abstract}

Index Terms-Rf magnetron sputtering, metal buffer layer, electrical properties, oxidation resistance.

\section{INTRODUCTION}

Chromium nitride $(\mathrm{CrN})$ coatings exhibit high hardness, good corrosion resistance, good wear resistance and low friction coefficient. They are widely used in cutting and forming tools, bearing and machine parts, dies and molds [1]-[7]. However, because of the occurrence of some new processes, such as high speed or dry machining, there are still industrial interests in protective coatings with further improved wear resistance, hardness and fracture toughness [8]-[11]. In such conditions, nanoscale multilayer coatings received much attention as they provide the flexibility to combine two materials with different structures and properties, which may bring to the new system not only the advantage owned by each constituent but also some characteristics superior than any component [12].

Many reports show that the preparation technology of high quality $\mathrm{CrN}$ films is still to be developed, and there are still some controversies about their characteristics. In addition, the research of metal/TiN multilayer films has made some progress [13], so the $\mathrm{CrN} /$ metal films need to be further studied [14]-[16]. Despite a significant number of works about the mechanical properties, hardness and wear

Manuscript received July 25, 2018; revised March 3, 2019. This work is supported National Natural Science Foundation of China under Grants 51272224 and 11164031.

Jia-Xin Zhang and Guang-Rui Gu are with the Department of Physics, College of Science, Yanbian University, Yanji 133002, China $\left({ }^{*}\right.$ Corresponding author: Guang-Rui Gu; e-mail: 986016416@qq.com,grgu@ybu.edu.cn). resistance of multilayer coatings, there is still a lack of information about the high temperature oxidation resistance and electrical properties [17]-[19]. In this work, the $\mathrm{CrN} / \mathrm{Cr}$ films were prepared by RF magnetron sputtering, followed by a systematic study by comparison method of the high temperature oxidation resistance and electrical properties.

\section{EXPERIMENTAL PROCEDURE}

$\mathrm{CrN} / \mathrm{Cr}$ films with good crystallinity were deposited on $\mathrm{Si}$ (100) substrates using a radio frequency (RF) magnetron sputtering system. A Cr target with $99.99 \%$ in purity was used and the substrate-to-target distance was kept at $60 \mathrm{~mm}$. First, the $\mathrm{Cr}$ metal buffer layer was deposited on a $\mathrm{Si}$ (100) substrate by RF magnetron sputtering in an atmosphere of $\mathrm{Ar}$ gas. And then $\mathrm{CrN}$ films were sputtered on the $\mathrm{Cr}$ metal buffer layer, and the working gas was a mixture of $\mathrm{Ar}$ (99.99\%) and $\mathrm{N}_{2}(99.99 \%)$ and the total gas flow rate was maintained at $100 \mathrm{sccm}$. Prior to deposition, the chamber was evacuated to a base pressure of $5 \times 10^{-5} \mathrm{~Pa}$, and the $\mathrm{Si}$ substrate is always pre-sputtered by $\mathrm{Ar}$ for $10 \mathrm{~min}$ in order to remove the oxide and contaminant layer. During deposition, the sputtering power was $100 \mathrm{~W}$, the ratio of $\mathrm{N}_{2}$ flow over the total flow $\left(\mathrm{N}_{2} /\left(\mathrm{N}_{2}+\mathrm{Ar}\right)\right)$ was $50 \%$ and the substrate bias was $100 \mathrm{~V}$. CrN films with a (111) preferred orientation at the best preparation condition were prepared. In the experiment, $\mathrm{CrN}$ films were annealed in air using a conventional furnace at $800^{\circ} \mathrm{C}$ during $1 \mathrm{~h}$.

The structure and chemical composition of coatings were investigated by X-ray diffraction (XRD) and energy dispersive $\mathrm{x}$-ray spectroscopy (EDX). The cross-section images of the multilayer coatings were observed by scanning electron microscopy. In order to get the information on the composition, molecular structure and valence states of the films, X-ray photoelectron spectroscopy (XPS) was measured. The resistivity of $\mathrm{CrN}$ films was measured by the four-probe method. The high temperature heat treatment of the sample was carried out in a high temperature sintering furnace.

\section{RESULTS AND DISCUSSION}

\section{A. Oxidation Resistance of $\mathrm{CrN} / \mathrm{Cr}$ Films}

The XRD patterns of $\mathrm{CrN} / \mathrm{Cr}$ films are shown in Fig. 1. The as-deposited coatings present a cubic structure with an intense (111) diffraction peak and a weak (222) diffraction peak, whereas no other peaks from the coatings are observed. 
The CrN/Cr films have good crystallinity before annealing. However, the cubic CrN/Cr layer after annealing is still the preferred growth direction, but its diffraction peak obviously reduced and the crystal quality of the film also decreased. A $\mathrm{Cr}_{2} \mathrm{~N}$-related diffraction peak and a number of chromium oxide diffraction peaks, such as $\mathrm{Cr}_{2} \mathrm{O}_{3}, \mathrm{CrO}_{3}$ and $\mathrm{CrO}_{2}$, appear on the surface of $\mathrm{CrN} / \mathrm{Cr}$ film after high temperature heat treatment. During the high temperature heat treatment, the occurrence of $\mathrm{Cr}_{2} \mathrm{~N}$ phase shows that the decomposition of cubic $\mathrm{CrN}$ is combined with $\mathrm{O}$ to form an oxygen compound, and a $\mathrm{Cr}_{2} \mathrm{~N}$ phase with a high temperature thermostable structure is formed. According to XRD analysis, there is still no Cr-related information.

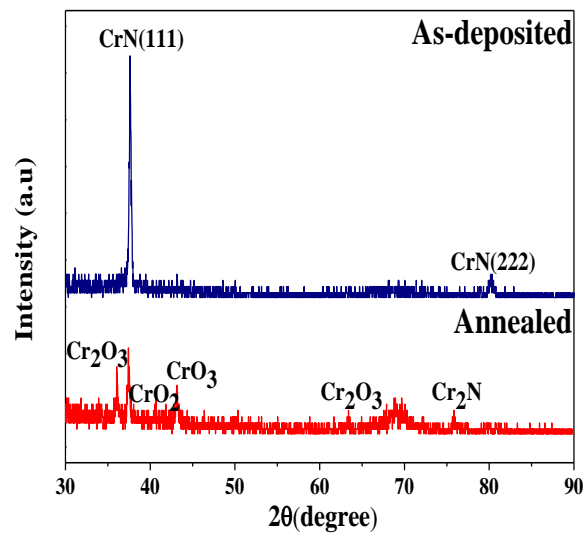

Fig. 1. XRD patterns of the as-deposited and annealed $\mathrm{CrN} / \mathrm{Cr}$ film.

Fig. 2 shows the surface and cross-sectional SEM images of the $\mathrm{CrN} / \mathrm{Cr}$ thin films. The as-deposited $\mathrm{CrN} / \mathrm{Cr}$ films have very fine grains with typical pyramidal tetrahedron structures, and there is a significant growth consistency between the $\mathrm{Cr}$ and $\mathrm{CrN}$ layers, as shown in Fig. 2(a) and (b) This growth consistency was also reported in the literature on TiN/Ti multilayers [20]. The (100) plane of the cubic structure of the $\mathrm{CrN}$ crystal has the smallest surface energy density, and the cubic $\mathrm{CrN}$ had a (111) direction preferential growth influenced by three (100) planes during the deposition process, so the pyramidal tetrahedron structure is formed [21]. Fig. 2(b) shows the cross-section SEM diagram of the $\mathrm{CrN} / \mathrm{Cr}$ films. It can be seen from the figure that there is no obvious boundary between the $\mathrm{Cr}$ and $\mathrm{CrN}$ layer, and shows a typical columnar growth structure.

The focal spot of the surface of the $\mathrm{CrNr}$ film and $\mathrm{CrN} / \mathrm{Cr}$ films is shown in Fig. 2(c, d), respectively. Under the bombardment of high-energy particles, not only the growth defects will be formed between the grains on the surface of the film, but also a bombardment focal spot will be formed on the surface of the film[22], [23]. As shown in Fig. 2(c), the flake bombardment of the focal spot on the surface of the film leads to the discontinuous crystallization, which can affect the increase of the resistivity of the film.

As shown in Fig. 2(e), the surface structure of the annealed $\mathrm{CrN} / \mathrm{Cr}$ thin film is completely destroyed and the pyramid structure disappears. The surface of the film is composed of grains with different sizes and different structures, and some grains are larger in size and have a sheet structure. XRD analysis shows that the surface structure of the $\mathrm{CrN} / \mathrm{Cr}$ film is seriously damaged, which is attributed to the more surface defects and larger grain size. In addition, the clear outline of the tetrahedron structure also increases contact area with atmosphere, and the crystal structure of the $\mathrm{CrN}$ becomes more unstable at high temperature, so the cubic $\mathrm{CrN}$ phase decomposition and oxidation is accelerated. The grain size and structure have an obvious influence on the high temperature oxidation resistance of the film. Fig. 2(f) shows a cross-sectional SEM image of the $\mathrm{CrN} / \mathrm{Cr}$ film after high temperature annealing. It can be seen that the surface failure of the film is seriously damaged and the columnar growth structure is deeply influenced.

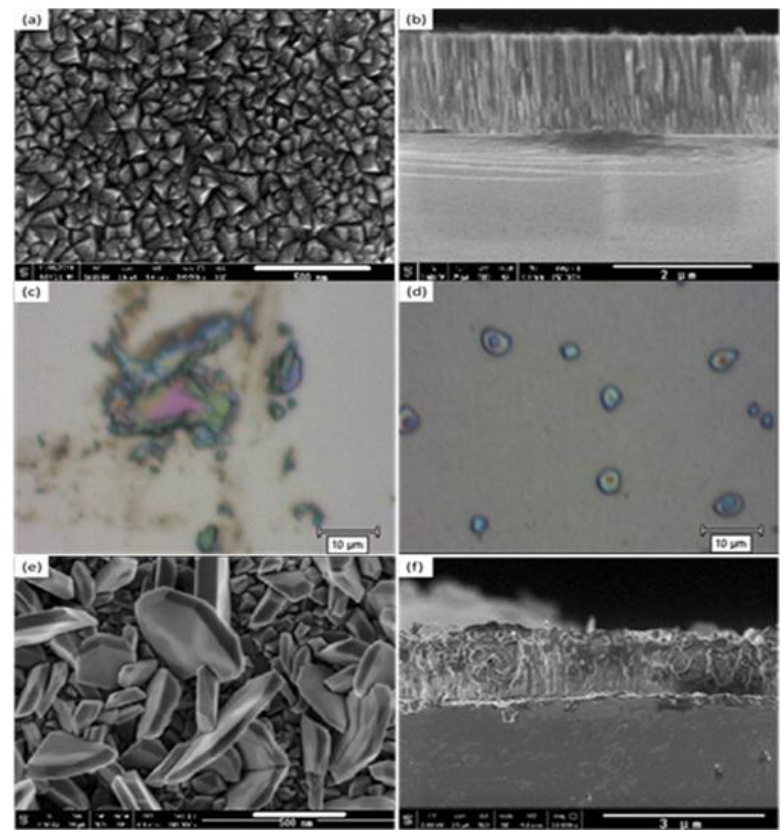

Fig. 2. Surface and cross section SEM images of CrN/Cr films: (a, b) as-deposited; (c, d) focal spot; (e, f) annealed.

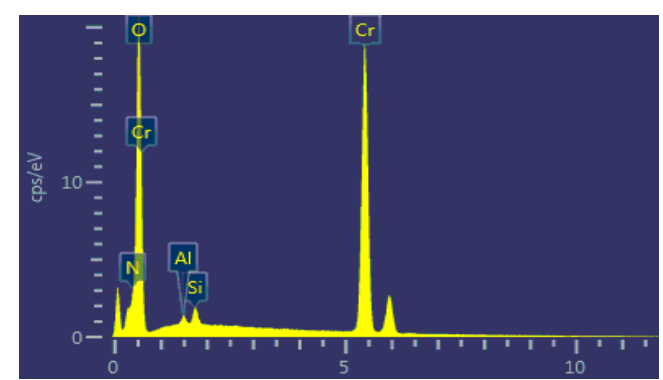

Fig. 3. EDX spectrum of $\mathrm{CrN} / \mathrm{Cr}$ films annealed at high temperature.

Fig. 3 shows the EDX spectrum after annealing at high temperature. EDX analysis results are shown in Table I. The results show that the $\mathrm{CrN} / \mathrm{Cr}$ film has a significant decrease in the content of $\mathrm{N}$ and a significant increase in the content of $\mathrm{O}$ element after annealing, and the ratio of the decrease and the increase of the $\mathrm{CrN} / \mathrm{Cr}$ film is larger, which also proves that the $\mathrm{O}$ element is adsorbed on the surface of the film and $\mathrm{Cr}-\mathrm{N}$ bond is more damaging. The $\mathrm{Al}$ element is derived from the impurities at the time of measurement.

Fig. 4 shows the XPS spectrum of the $\mathrm{Cr}, \mathrm{N}$, and $\mathrm{O}$ elements of the $\mathrm{CrN} / \mathrm{Cr}$ film after annealing. As shown in Fig. 4(a), after the high temperature annealing, there are the three distinct peaks of $\mathrm{Cr} 2 \mathrm{p}^{1 / 2}, \mathrm{Cr} 2 \mathrm{p}^{3 / 2}$ and $\mathrm{O} 1$ s located at 585.06 $\mathrm{eV}, 575.66 \mathrm{eV}$ and $532.28 \mathrm{eV}$ [26], respectively. The selected area N1s peak inserted in Fig. 4(a) shows the 
intensity of the peaks after annealing is significantly reduced, which also indicates that a large part of the $\mathrm{N}$ element diffuses into the film at high temperature annealing. Fig. 4(b) shows the single XPS spectrum of $\mathrm{Cr} 2 \mathrm{p}^{3 / 2}$ of the $\mathrm{CrN} / \mathrm{Cr}$ film, the results show that the Cr-related compounds in the annealing process have changed significantly. The information about the metal $\mathrm{Cr}$ does not appear in the XPS spectrum, which again shows that the metal $\mathrm{Cr}$ has been completely transformed at $800^{\circ} \mathrm{C}$ high temperature.

\begin{tabular}{cccc}
\multicolumn{4}{c}{ TABLE I: EDX ANALYSIS RESULTS OF THE ANNEALED CRN/CR FILMS } \\
\hline Element & Apparent concentration & Wt.\% & At.\% \\
\hline $\mathrm{N}$ & 9.64 & 0.40 & 8.04 \\
$\mathrm{O}$ & 47.17 & 27.43 & 51.35 \\
$\mathrm{Cr}$ & 53.21 & 66.91 & 36.14 \\
$\mathrm{Si}$ & 2.08 & 1.22 & 2.53 \\
$\mathrm{Al}$ & 0.49 & 0.04 & 0.76 \\
\hline
\end{tabular}

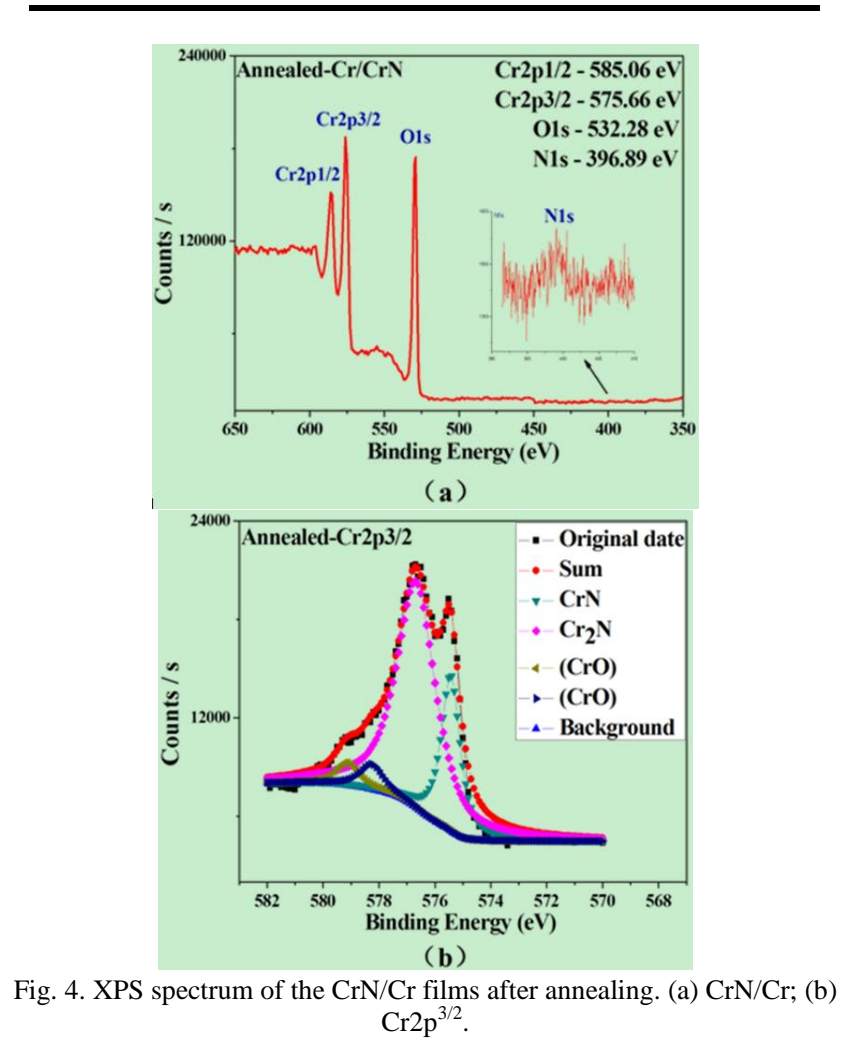

As shown in Table II, the cubic CrN of the film surface gradually decomposed and changed to $\mathrm{Cr}_{2} \mathrm{~N}$ and $\mathrm{CrO}$ after high temperature heat treatment. In addition, we found that the total $(\mathrm{CrO})$ content of $\mathrm{CrN} / \mathrm{Cr}$ films was relatively high after annealing. It was also known that the $\mathrm{CrN} / \mathrm{Cr}$ film surface was highly damaged from XRD and SEM analysis, which can accelerate the oxidation of $\mathrm{CrN} / \mathrm{Cr}$ thin films. The oxidized form of the film surface: on the one hand, the diffusion of $\mathrm{O}$ elements from the air into the interior of the film, destroying the chemical bonds between $\mathrm{Cr}$ and $\mathrm{N}$, and recombining with $\mathrm{Cr}$-bonds to form various chromium oxide [24]-[26]; On the other hand, $\mathrm{CrO}_{3}$ decomposes into $\mathrm{CrO}_{2}$ which is easily converted to more stable $\mathrm{Cr}_{2} \mathrm{O}_{3}$ at high temperatures, and $\mathrm{CrO}_{3}$ also undergoes a transition to $\mathrm{Cr}_{2} \mathrm{O}_{3}$ [27]. Some literature reports show that chromium oxide has similar Gibbs free energy, so that different oxides can simultaneously exist in the samples [28].
TABLE II: XPS ANALYSIS RESULTS OF CRN FILMS ON CR METAL BUfFER AFTER ANNEALING

\begin{tabular}{lllll}
\hline $\begin{array}{l}\text { Binding } \\
\text { energy }(\mathrm{eV})\end{array}$ & FWHM & Area & $\begin{array}{l}\text { Area } \\
\text { Percent }\end{array}$ & Compound \\
\hline 575.43 & 0.8 & 11200 & $22.85 \%$ & $\mathrm{CrN}$ \\
576.67 & 1.65 & 33540 & $68.42 \%$ & $\mathrm{Cr} 2 \mathrm{~N}$ \\
578.26 & 1 & 2240 & $4.57 \%$ & $(\mathrm{CrO})$ \\
579.13 & 1 & 2040 & $4.16 \%$ & $(\mathrm{CrO})$ \\
\hline
\end{tabular}

Through the above research and analysis, the transformation of the $\mathrm{CrN} / \mathrm{Cr}$ films at high temperatures can be described by the following reactions:

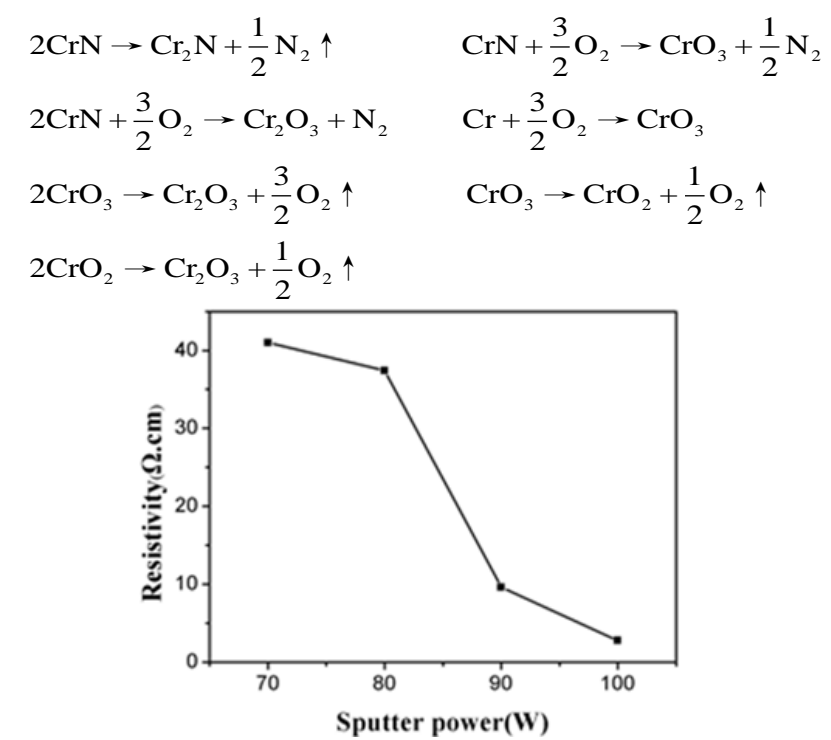

(a)

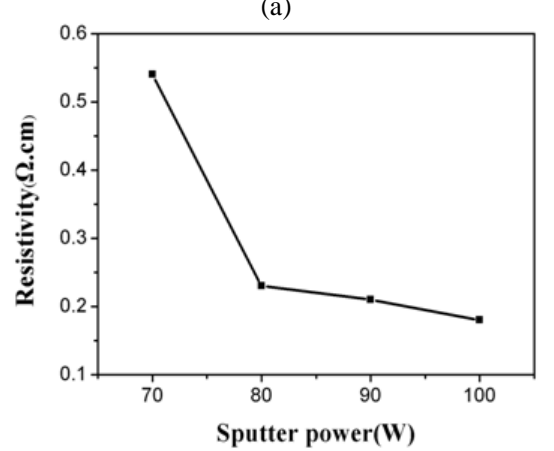

(b)

Fig. 5. The resistivity of (a) $\mathrm{CrN}$ and (b) $\mathrm{CrN} / \mathrm{Cr}$ films deposited at different power.

\section{B. Electrical Properties of CrN/Cr Films}

The resistivity in the $\mathrm{CrN}$ films and $\mathrm{CrN} / \mathrm{Cr}$ films decrease to a minimum as the power increases from $70 \mathrm{~W}$ to $100 \mathrm{~W}$ (solid data points in Fig. 5(a) and Fig. 5(b) ), this is consistent with the crystallinity of the film obtained with XRD analysis. The $\mathrm{CrN}$ films have a relatively low resistivity under the best deposition conditions. Compared with $\mathrm{CrN}$ films, the resistivity of $\mathrm{CrN} / \mathrm{Cr}$ films is obviously decreased with one or two orders of magnitude difference. The main reason is that the impact of $\mathrm{Cr}$ metal buffer layer makes the cubic $\mathrm{CrN}$ crystal positive tetrahedral structure is clear and has a larger grain size, and more grain boundaries, which led to the film resistivity is small [29]. In addition, due to the existence of $\mathrm{Cr}$ buffer layer, the focal spot size decrease, the carrier concentration of the films increases, 
thus the roughness and scattering effect decrease, which further reduces the resistivity.

\section{CONCLUSIONS}

$\mathrm{CrN}$ films were deposited on a $\mathrm{Cr}$ metal buffer layer by RF magnetron sputtering technique. The electrical characteristics and high temperature oxidation resistance of $\mathrm{CrN} / \mathrm{Cr}$ films were analyzed systematically. The main factors affecting the oxidation resistance and thermal stability of the film are: (1) the influence of the crystal structure on the surface. The clear pyramid structure reduces the thermal stability of the films at high temperature, and further promotes the oxidation degree of the films. (2) The presence of $\mathrm{Cr}_{2} \mathrm{~N}$ phase leads to the increase of the thermal stability of the film and the further oxidation of the film, and the formation of the $\mathrm{Cr}_{2} \mathrm{O}_{3}$ phase at high temperature also prevents the further oxidation of the film. There are two main factors affecting the resistivity of

CrN film: (1) the influence of the crystal quality of the film. As the crystalline quality of the film increases, the mobility of the carrier in the film increases and then the resistivity of the film decreases. (2) The influence of the film size and surface defects. The resistivity is reduced because that the number of grain boundaries are increased by the coarser grain size and surface defects making.

\section{REFERENCES}

[1] J. Lin, Z. L. Wu, X. H. Zhang, B. Mishra, J. J. Moore, and W. D. Sproul, "A comparative study of $\mathrm{CrNx}$ contings synthesized by dc and pulsed dc magnetron sputtering," Thin Solid Films, vol. 517, p. 1887, 2009.

[2] S. Shin, M. Kim, M. Kang, K. Kim, D. Kwon, and J. Kim, "Cutting performance of $\mathrm{CrN}$ and $\mathrm{Cr}-\mathrm{Si}-\mathrm{N}$ coated end-mill deposited by hybrid coating system for ultra-high speed micro machining," Surf Coat Technol., vol. 202, p. 5613, 2008.

[3] P. H. Mayrhofer, H. Willmann, and C. Mitterer, "Oxidation kinetics of sputtered Cr-N hard coatings," Surf Coat Technol., 2001.

[4] L. Cunha, M. Andritschky, L. Rebouta, and K. Pischow, "Corrosion of $\mathrm{CrN}$ and TiAlN coatings in chloride-containing atmospheres," Thin Solid Films, pp. 116-119, 1152, 1999.

[5] S. J. Bull and D. S. Rickerby, "Compositional, microstructural and morphological effects on the mechanical and tribological properties of chromium nitrogen films," Surf. Coat. Technol., pp. 732-744, 1990.

[6] P. Hones, R. Consiglio, N. Randall, and F. Lévy, "Mechanical properties of hard chromium tungsten nitride coatings," Surf. Coat. Technol., vol. 125, pp. 179-184, 2000.

[7] P. Hones, C. Zakri, P. E. Schmid, F. Lévy, and O. R. Schojaei, "Oxidation resistance of protective coatings studied by spectroscopic ellipsometry," Appl. Phys. Lett., vol. 76, no. 22, pp. 3194-3196, 2000.

[8] E. Martinez, R. Sanjinés, O. Banakh, and F. Lévy, "Electrical, optical and mechanical properties of sputtered $\mathrm{CrNy}$ and $\mathrm{Cr} 1-\mathrm{xSixN} 1.02$ thin films," Thin Solid Films, vol. 332, pp. 447-448, 2004.

[9] Z. H. Xie, M. Hoffman, P. Munroe, A. Bendavid, and P. J. Martin, "Deformation mechanisms of TiN multilayer coatings alternated by ductile or stiff interlayers," Acta Mater, vol. 56, p. 852, 2008.

[10] P. C. Wo, P. R. Munroe, Z. Jiang, Z. F. Zhou, K. Y. Li, and Z. H. Xie, "Enhancing toughness of $\mathrm{CrN}$ coatings by $\mathrm{Ni}$ addition for safety-critical applications," Mater Sci Eng A, vol. 596, p. 264, 2014.

[11] J. Musil and J. Vlček, "Magnetron sputtering of hard nanocomposite coatings and their properties," Surf Coat Technol., pp. 142-144, vol. $557,2001$.

[12] C. X. Tian, B. Yang, S. J. Yan, Z. H. Lu, Z. H. Huang, and D. J. Fu, "Influence of substrate rotation speed on the structure and mechanical properties of AlTiN/CrN coatings," 2013, pp. S228-S232.

[13] T. W. Liu, C. Dong, and S. Wu, "TiN, TiN gradient and Ti/TiN multi-layer protective coating on uranium," Surface \& Coating Technology, vol. 201, no. 15, pp. 6737-6741, 2007.
[14] N. E. Beliardouh, K. Bouzid, C. Nouveau, B. Tlili, and M. J. Walock, "Tribological and electrochemical performances of $\mathrm{CrN} / \mathrm{Cr}$ and $\mathrm{CrN} / \mathrm{Cr} / \mathrm{CrAlN}$ multilayer coatings deposited by RF magnetron sputtering," Tribology International, vol. 82, pp. 443-452, 2015.

[15] D. F. Arias, A. Gómez, J. M. Vélez, R. M. Souza, and J. J. Olaya, "A mechanical and tribological study of $\mathrm{CrN} / \mathrm{Cr}$ multilayer coatings," Materials Chemistry and Physics, vol. 160, pp. 131-140, 2015.

[16] T. Polcar, R. Martinez, T. Vítů, L. Kopecký, R. Rodriguez, and A. Cavaleiro, "High temperature tribology of $\mathrm{CrN}$ and multilayered CrN/Cr coatings," Surface and Coatings Technology, vol. 203, no. 20, 2009.

[17] Y. Otani and S. Hofmann, "High temperature oxidation behaviour of (Ti1-xCrx)N coatings," Thin Solid Films, vol. 287, pp. 188-192, 1996.

[18] B. Günter, F. Christoph, B. Erhard, and B. Christina, "Development of chromium nitride coatings substituting titanium nitride," Surface and Coatings Technology, pp. 184-191, 1996.

[19] D. Dubiel, "Characterization of sputter deposited chromium nitride coatings," Prakt. Met., vol. 26, pp. 68-82, 1989.

[20] J. Wang, "Preparation and properties of reactive magnetron sputtering metal / TiN multilayer films and metal doped TiN films[D]," Yanbian University , 2012.

[21] W. Tan, L. J. Deng, K. W. Xu, and J. Lu, "Relationship between resistivity of metal film and surface roughness and residual stress," Rare Metal Materials and Engineering, vol. 37, no. 4, 617-620, 2008.

[22] Y. L. Li and S. Kim, "Effects of deposition parameters on the mechanism and properties of magnetron sputtering $\mathrm{CrNx}$ films," Modern Instruments, vol. 1, pp. 22-24, 2010.

[23] V. Chawla, R. Jayaganthan, and R. Chandra, "Structural characterizations of magnetron sputtered nanocrystalline TiN thin films," Materials Characterization, vol. 59, no. 8, pp. 1015-1020, 2008.

[24] G. B. Zhao, X. Y. Cao, D. C. Luan, and C. Y. Chen, "Preparation of $\mathrm{CrN}$ thin films and study on their oxidation resistance," Tool Technology, vol. 45, no. 2, 46-49, 2011.

[25] A. Lippitz and T. H. Hübert, "XPS investigations of chromium nitride thin films," Surface and Coatings Technology, vol. 200, pp. 250-253, 2005.

[26] I. Milosev, H. H. Strehblow, and B. Navinsek, "XPS in the study of high-temperature oxidation of $\mathrm{CrN}$ and TiN hard coatings," Surface \& Coating Technology, pp. 897-902, 1995.

[27] J. Dho, D. H. Kim, D. Kwon, and B. D. Kim, "Thermal instability of the half-matallic $\mathrm{CrO}_{2}$ film epitaxially grown on $\mathrm{TiO}_{2}$," Journal of Applied Physics, vol. 104, no. 6, 2008.

[28] E. Ando and S. Suzuki, "Optical and mechanical properties of $\mathrm{Cr}$ and CrNx films by dc magnetron sputtering," Journal of Non-Crystalline Solids, vol. 218, pp. 68-73, 1997.

[29] J. C. Yang, X. Q. Meng, C. T. Yang, and Y. Zhang, "Influence of sputtering power on crystal quality and electrical properties of Sc-doped AlN film prepared by DC magnetron sputtering," Applied Surface Science, vol. 287, pp. 355-358, 2013.

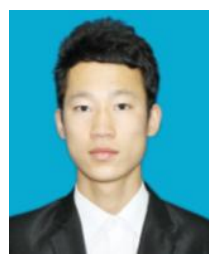

Jia-Xin Zhang was born in Huadian, Jilin province on February 24, 1993. He is a under graduate student, he majored in condensed matter physics of Yanbian University. His main research direction is functional material physics.

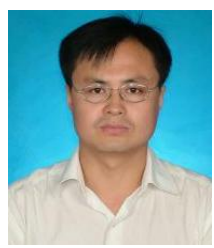

Guang-Rui Gu is a professor of Yanbian University. His main research interests are manganese oxide nanomaterials, nanostrcture carbon films, transparent conductive films and transition metal nitride/oxide films.

His main publications are: G. R. Gu and T. Ito, "Field emission characteristics of thin-metal-coated nano-sheet carbon films," Applied Surface Science, vol. 257, no. 7, pp. 2455-2460, 2011; L. L. Lan, G. R. Gu et al., "Manganese oxide nanostructures: Low-temperature selective synthesis and thermal conversion," RSC Adv., vol. 5, pp. 25250-25257, 2015; B. Xu, X. G. Ren G. R. Gu et al., "Structural and optical properties of $\mathrm{Zn}$-doped $\mathrm{SnO}_{2}$ films prepared by DC and RF magnetron co-sputtering," Superlattices and Microstructures, vol. 89, pp. 34-42, 2016. 